\section{Nuclear fuel report out}

After three and a half years of study, the Swedish Commission on Spent Nuclear Fuel and Radioactive Waste recently produced its final report. Wendy Barnaby sent this view from Stockholm.

"Even today's techniques offer satisfactory possibilities for the handling and storage of spent nuclear fuel and radioactive waste." Such is the assessment of the Swedish Commission on Spent Nuclear Fuel and Radioactive Waste, whose task was to study the management of low-, medium- and high-level radioactive wastes-that is, not only those from nuclear power plants, but also those from research institutions, hospitals and industry.

The timing of the report was no doubt planned to support the government's pro-nuclear power stance in the current general election campaign, in which the ruling Social Democrats are under heavy pressure from the opposition-part of which is adamantly opposed to nuclear power. Thus the report's claim-that its "central demand" was that all steps in the handling of radioactive waste had to be formulated with regard to the protection of people and their environment now and in the future-sounds suspiciously like an attempt to pull the carpet out from underneath the opposition, whose criticism of the safety and environmental aspects of nuclear power has mobilised an unusually large following. The latest opinion polls show that both government and opposition parties have lost support for their nuclear energy platforms since last January and that, while the opposition's policy is still more popular than the government's, more people are doubting the wisdom of either. This result will obviously stimulate each camp to even greater propaganda efforts than before, and the Commission's report will undoubtedly be one of the government's main weapons.

The report has not definitely pronounced on the fate of Sweden's spent fuel. "We recommend that this decision should be taken in 1981 or 1982", says the Commission's Secretary, Mr Philip Moding. The options are to continue sending spent fuel abroad for reprocessing, or to deal with it in Sweden reprocessed or not. In the long term, sending it abroad is no satisfactory solution. Under an agreement that will last until 1980 , spent fuel from the Oskarshamn plant is being sent for reprocessing to Windscale in England. Negotiations are presently going on between the Swedish
Nuclear Fuel Supply Company (SKBF) and United Reprocessors, jointly owned by British, French and German interests, for the spent fuel that will be taken from plants already in operation at Ringhals, Forsmark and Barsebäck. A preliminary understanding has been reached but nothing has been signed; and the hoped-for agreement would probably only last until 1980 anyway. "It will be necessary for us to build an intermediate storage capacity for spent fuel in any case", says the Director of SKBF and an expert adviser to the Commission, Dr Erik Svenke, "because even if we continue to send spent fuel abroad, the reprocessor will have the right to return the waste to Sweden and we would then have to store it here."

The report urges the acceleration of research into ways of handling spent fuel domestically without reprocessing. How seriously this proposition is meant is hard to say. A domestic solution will in the long term certainly be preferred to the difficulties and uncertainties of sending it abroad, especially as Sweden's neutrality makes the country seek as much independence as possible in questions related to its national security; and it seems almost certain that a reprocessing plant, with its attendant business opportunities and relative simplification of storage of remaining waste, will then seem the best solution. Dr Svenke is convinced that Sweden will have to build a reprocessing plant at some time. "A country with a civil nuclear programme has a responsibility to take care of its waste", he says.

According to the report, any decision to build such a plant should go hand in hand with one to construct a fuel fabrication plant, to ensure that both plutonium and uranium are re-used as fuel. It cstimates that a reprocessing plant with a capacity of 800 tons of uranium a year (and offering employment for 1,000 people) would take about 13 years to build. The Social Democrats' plans for Sweden's nuclear future envisage 13 reactors in operation by 1985 . So far, five are running and five others are under construction. When all are operating, the country's total net nuclear power capacity will be about $10 \mathrm{GWe}$ and, it is estimated, the reactors will produce about 300 tons of spent fuel a year. The reprocessing plant's excess capacity would be intended for other countries' waste. The Nordic countries would be obvious participants, although neither Denmark nor Norway has yet decided to build nuclear power plants. Finland, however, had three under construction at the beginning of this year, and it is expected that they will produce about 2.2 GWe by 1985 .

The method of disposal recommended by the Commission is to melt the highly radioactive waste in glass and deposit the medium- and low-level waste in concrete, then store it all in vertical tunnels drilled out of bedrock at a depth of 300-400 metres. Studies made by the Geological Survey of Sweden have pronounced bedrock conditions stable and suitable for such storage. "It is very important that the Commission has demonstrated that the terminal storage problem can be solved in Swedish bedrock", says Dr Svenke. "It signifies that the fuel cycle can in fact be closed."

The President of Sweden's Friends of the Earth group, Lennart Daléus, however, is not so optimistic. "What the Commission is telling us", he maintains, "is that with current techniques and those they hope will be developed in the future, the problems of highlevel radioactive waste disposal can be solved. But in fact this is more a hope than a technical certainty." $\mathrm{He}$ also raises broader issues which he says the report should have considered. What are the social and moral implications of undertaking to secure radioactivity for hundreds of years? How can we possibly be sure that future political regimes will be willing or able to take care of our waste? Dr Svenke does not think these issues are relevant. "The terminal storage of radioactive waste", he says, "is surely a technical problem. It does not have the same dimensions as other aspects of the question: the relationship between the spread of nuclear energy and the proliferation of nuclear weapons, for example"although he is apparently prepared to take the risk of proliferation.

The report gives only a brief mention to the problems of terrorism and theft of plutonium, and it is noteworthy that one of the parliamentary members of the Commission, John Takman, felt obliged to publish an addendum to the report expressing his regret that the Commission had not taken more account of the relationship between nuclear energy and nuclear weapons. If the more pessimistic experts are proved right, and the spread of civil nuclear energy programmes does result in nuclear-weapon proliferation which does in turn produce global nuclear catastrophe, all the present arguments will be shown to be ironically irrelevant.

Such predictions, however, are not the stuff electoral victories are made of. Sweden's nuclear future will have to wait for clarification until September, when the results are known. 